\title{
A CAPES e sua condição como agência reguladora da educação em nível de pós-graduação no Brasil d
}

\section{CAPES and its condition as a regulatory agency for post-graduate education in Brazil}

\author{
Nicolas Addor (iD \\ Doutorando em Direito (PUC-PR) \\ Pontifícia Universidade Católica do Paraná (PUC-PR) \\ Curitiba, Paraná, Brasil \\ E-mail: nicolasaddor@gmail.com
}

\author{
Marcos Viana Costódio \\ Mestre em Direito Econômico (PUC-PR) \\ Pontifícia Universidade Católica do Paraná (PUC-PR) \\ Curitiba, Paraná, Brasil \\ E-mail:marcos@cecadv.com
}

\begin{abstract}
Resumo: A pesquisa pretende analisar a estrutura jurídico-administrativa da Coordenação de Aperfeiçoamento de Pessoal de Nível Superior - CAPES e sua relevância para a regulação da pós-graduação stricto sensu brasileira, buscando, assim, demonstrar que a entidade possui, de fato, a condição de agência reguladora. Para isso, é necessário abordar três pontos, utilizando, para tanto, metodologia dedutiva, com fontes bibliográficas e documentais relacionados à entidade: $O$ primeiro ponto busca descrever e contextualizar a formação da fundação CAPES, bem como relatar as atividades administrativas que exerce sobre a pós-graduação. No segundo ponto, aborda-se sobre o processo histórico de surgimento das agências reguladoras, analisando também os objetivos e atribuições a elas incumbidas. Por fim, no terceiro ponto, expôs-se, de maneira crítica, considerações sobre a condição da CAPES como agência reguladora. Dessa maneira, compreende-se que uma fundação pública, quando atende uma função típica do Estado, não é, apesar do que formalmente a lei que a instituiu afirma, uma fundação, mas sim, ao contrário, uma autarquia, o que possibilita compará-la com uma agência reguladora. Conclui, assim, que em razão dos extensos poderes que a CAPES exerce sobre os programas de pósgraduação, a sua natureza autárquica e por regular uma atividade econômica, em sentido amplo, considera-se que ela é na realidade uma agência reguladora da pós-graduação brasileira. Além disso, dado o esvaziamento terminológico da noção de agência, a condição diferenciada dos dirigentes não é um fator relevante para a categorização de um ente da administração indireta como agência.
\end{abstract}

Palavras-chave: Pós-graduação stricto sensu. Agência reguladora. Regulação dos serviços públicos. Políticas públicas. Educação superior.

\begin{abstract}
The research intends to analyze the legal and administrative structure of the Coordination of Improvement of Higher-Level Personnel - CAPES and its relevance to the regulation of the stricto sensu Brazilian postgraduate course, in order to demonstrate that the entity has, in fact, the condition of regulatory agency. For this, it is necessary to address three points using deductive methodology with bibliographic and documentary sources related to CAPES: The first point seeks to describe and contextualize the formation of the CAPES foundation, as well as to report the administrative activities that it exerts on the post-graduation. In the second point, it addresses the historical process of the emergence of regulatory agencies, also analyzing the objectives and attributions assigned to them. Finally, in the third point, a critical analysis was made of the condition of CAPES as a regulatory agency. In this way, it is understood that a public foundation, when it serves a typical function of the State, is not, despite what formally the law that instituted it, a foundation, but rather, an autarchy, which makes it possible to compare it, with a regulatory agency. It concludes, therefore, that because of the extensive powers that CAPES exercises over postgraduate programs, its autarkic nature and regulating an economic activity in a broad sense, it is considered that it is in reality a regulatory agency for post- graduation. Moreover, given the terminological emptying of the notion of agency, the differentiated condition of the managers is not a relevant factor for the categorization of a body of indirect administration as an agency.
\end{abstract}


Keywords: Post-graduation stricto sensu. Regulatory agency. Regulation of public services. Public policy. College education.

Data de recebimento: $24 / 01 / 2019$

Data de aprovação: 17/02/2020

\section{Introdução}

Crê-se que a CAPES exerce um poder de polícia, controle, fomento e poder normativo das atividades educacionais de pós-graduação de maneira tão significativa que as barreiras de entrada e saída da atividade econômica são altamente complexas. Uma entidade com amplo poder, capaz de mandar encerrar programas, regular a qualificação dos trabalhadores, exigir padrões de qualidade, autorizar ou negar a abertura de novos programas de pós-graduação, estabelecer obrigatoriedade de cooperação entre os PPG'S, fiscalizar a produtividade e infraestrutura, exigir contribuições para com a comunidade é observado, também, nas agências reguladoras de serviço público.

Apesar de inegável a contribuição institucional da fundação para a pós-graduação brasileira, é ela, como última instância, que coordena os rumos da pós-graduação, de acordo com os planos de desenvolvimento nacional da administração direta. O amplo poder delegado à entidade faz ela se afastar da sua condição de fundação pública, aproximando-se do status de agência reguladora segundo os objetivos traçados e as atividades reguladas de cada ente da Administração Indireta segundo os estudos do Direito Administrativo.

O artigo está dividido em três tópicos. O primeiro explanará sobre a organização da CAPES na Administração Pública brasileira. Aqui, abordar-se-á uma contextualização sobre seu surgimento e, num segundo momento, será feita uma apresentação quanto à sua estrutura jurídico-administrativa.

Mais à frente, será discorrido sobre o instituto da agência reguladora e pontuações acerca da não inovação jurídica em relação aos outros entes da administração indireta. Por último, diante do espaço conquistado pelas agências no exercício do Poder regulador e de fomento em áreas sensíveis à concretização de direitos fundamentais, é necessário explanar em relação às suas atribuições e objeto.

Por fim, o terceiro e último tópico será reservado para as considerações sobre o status jurídico da CAPES de agência reguladora que de fato possui. O objeto, nesse ponto, será trazer argumentos sobre a real posição de agência reguladora sobre o serviço público de educação e ciência e tecnologia.

Em síntese, os argumentos propostos podem ser divididos em três categorias: a) o amplo poder regulatório da CAPES sobre uma atividade econômica em sentido lato; b) o impacto direto e indireto sobre as instituições de ensino superior e a sociedade em geral que o poder regulatório e o fomento realizado pela fundação realizam; e c) a irrelevância, para a categorização de uma autarquia como agência reguladora, da previsão em lei instituidora e pouca importância da estabilidade mandamental para os seus dirigentes.

\section{A organização e objetivos da CAPES}

A CAPES, no momento, é responsável por duas principais atividades na pós-graduação: regulação e fomento. Elas são exercidas por meio da avaliação da pós-graduação stricto sensu, ao acesso e divulgação da produção científica, investimentos na formação de recursos de alto nível no Brasil e internacionalmente, na 
promoção da cooperação científica nacional e no fomento da formação de professores na educação básica. (CAPES, 2018).

É por meio da atividade regulatória que a fundação garante a autonomia universitária e seu vínculo com o desenvolvimento nacional. Isso porque, o exercício da autonomia científica, embora seja pleno, restringe-se a esferas específicas previamente delimitadas pelo Poder Público. Assim, a liberdade científica encontra duas restrições: liberdade versus dignidade humana, que proíbe que a pesquisa afete a privacidade, moralidade e integridade física e, liberdade versus finalidade social, compreendendo-se que o desenvolvimento das pesquisas deve alcançar fins sociais, desenvolvendo alguma área sensível da sociedade. (ADDOR, 2018). ${ }^{1}$

Ademais, para Luiz Antônio Constant Rodrigues da Cunha, o ensino na pós-graduação possui uma função técnica, que incumbe à instituição de ensino superior formar professores e profissionais competentes para a expansão do ensino superior, o desenvolvimento da pesquisa científica e o desenvolvimento nacional e uma função social, que visa "restabelecer o valor econômico e simbólico² do ensino superior". (CUNHA, 1974, p. 67-69).

Relativamente ao fomento, conforme pondera Luiz Fernando de Paula, os projetos de inovação, podendo estender essa percepção ao desenvolvimento científico, não podem ser avaliados de maneira simples devido à sua incerteza. Isso obriga que as especificidades do processo de desenvolvimento científico devem ser levadas em conta na análise, uma vez que a pesquisa e desenvolvimento possuem características que a tornam diferente do investimento comum. (PAULA, 2014, p. 139) Entretanto, se foi incumbido à fundação o fomento ao desenvolvimento científico, ressalva Vanice Regina Lírio do Valle (2016, p. 183) que será inútil o reconhecimento do dever constitucional de articulação de políticas públicas como caminho de efetividade dos direitos fundamentais se essas não se revelarem úteis ao desvelamento em favor da cidadania.

De acordo com a lei instituidora, a CAPES detém quatro órgãos principais de direção: o Conselho Superior, a Diretoria, o Conselho Técnico-Científico da Educação Superior e o Conselho Técnico Científico da Educação Básica. O funcionamento e organização da estrutura interna da CAPES devem ser estabelecidos por um estatuto.

Como parte do exercício de sua atividade regulatória da pós-graduação, a fundação avalia quadrienalmente os programas de pós-graduação, tendo a última avaliação ocorrido entre 2013-2016 e divulgadas em 2017. De acordo os critérios da última avaliação, os programas possuem um conceito, mediante a atribuição de uma nota de 1 a 7 , sendo a classificação 1 e 2 como "insuficiente" e "fraco" respectivamente; a nota 3 como o padrão mínimo de qualidade para continuar pertencendo ao Sistema Nacional de Pós-Graduação e recomendação ao Conselho Nacional de Educação; a nota 4 é atribuída àquele programa considerado "bom";

\footnotetext{
1 Sobre autonomia universitária, Guilherme Henrique Hamada entende que "a linha divisória entre autonomia e regulação não é estanque e deverá ser fixada no caso concreto. Todavia, alguns aspectos estão bem consolidados de ambos os lados. Para que seja de qualidade, a educação depende de estruturas adequadas, professores qualificados e recursos para o aprendizado. Para formar seus alunos em consonância com sua identidade, as instituições precisam de autonomia para definir seus princípios e valores, sua metodologia de ensino e sua relação com outras instituições e com a sociedade. [...] O princípio da autonomia universitária garante liberdade de atuação às instituições de ensino superior, mas não é ilimitado. Contrapõemse à autonomia o dever do Poder Público de garantir qualidade de ensino. Em: Hamada (2017, p. 190-191).

2 "A organização do ensino pós-graduado, em particular, e a diferenciação do ensino superior, em geral (incluindo-se os cursos de curta duração) constituem mais uma etapa na transição dos padrões de discriminação desse grau de ensino. Antes a discriminação era feita pela divisão entre os concluintes do ensino médio que entravam no ensino superior e os que não entravam; agora se faz pelo modo como se sai do ensino superior, com diploma de que valor: curso de graduação de curta ou longa duração, curso de pós-graduação, mestrado ou doutorado". Em: Cunha (1974, p. 69).
} 
a nota 5 é destinada ao programa que obtenha classificação "muito bom", sendo essa nota a máxima aos programas que ofereçam apenas mestrado; as notas 6 e 7 são reservadas aos programas com doutorado que tiveram o predomínio do conceito "muito bom" (nota 6) ou, no caso do conceito 7, a ocorrência da nota "muito bom" em todos os quesitos da ficha de avaliação. ${ }^{3}$

Os critérios de avaliação são elaborados pelas coordenadorias de cada área do conhecimento e aprovadas pelo CTC-ES. Ademais, há duas instâncias responsáveis pela apreciação dos PPG'S: as Comissões de avaliação de cada área do conhecimento, que lhe competem a análise dos dados relativos às atividades dos programas e, a segunda instância, exercida pelo CTC-ES, que delibera sobre os resultados da avaliação com base nas fichas de avaliação de cada programa e nos relatórios que foram elaborados pelas comissões de avaliação. ${ }^{4}$

De acordo com a Portaria n. 959 de 2017 da CAPES, os quesitos para avaliação dos programas acadêmicos são: a proposta do programa (infraestrutura; coerência, atualização e abrangência das áreas de concentração; e planejamento), o corpo docente (titulação; diversificação na origem de formação; experiência; adequação com o programa; distribuição das atividades de pesquisa; e contribuição dos docentes à atividade de ensino e pesquisa na graduação), corpo discente, teses e dissertações (quantidade de teses e dissertações defendidas; distribuição das orientações entre os docentes; qualidade da produção científica do programa; eficiência na formação de mestres e doutores bolsistas), a produção intelectual (publicações qualificadas; produção artística; e produção técnica) e inserção social (impacto regional/nacional do programa; visibilidade e transparência na atuação do programa; integração com outros programas e centro de pesquisa).

Nos programas profissionais, os critérios são bastantes semelhantes aos quesitos avaliativos dos programas acadêmicos, diferenciando-se pelos seguintes itens: no quesito "proposta do programa", são considerados os itens "interação efetiva com outras instituições, atendendo a demandas sociais, organizacionais ou profissionais" e "formação de profissionais capacitados para a solução de problemas"; e no quesito "corpo discente e trabalho de conclusão", avalia-se a aplicabilidade dos trabalhos produzidos. ${ }^{5}$

Para Margarete Axt (2004, p. 69/83), a avaliação dos programas de pós-graduação, apesar de necessária, não é suficiente. Além do processo avaliativo, deve-se criar estratégias de intervenção para o engendramento de novos agenciamentos, indo contra o pensamento homogêneo, que individualiza e cria uma competição excludente entre os PPG's. Ademais, a autora critica a ausência de autonomia para a tomada de decisões quanto aos aspectos a serem valorizados pelo próprio Programa, defendendo que hajam avaliações mais democráticas e que considere as avaliações qualitativas que levem em conta a história de cada programa na busca de seu desenvolvimento. A padronização e o estabelecimento de rankings é uma política de homogeneização entre as diferentes áreas do conhecimento.

\footnotetext{
3 Portaria n. 959 , de 21 de março de 2017.

4 Portaria n. .59 , de 21 de março de 2017.

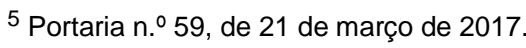


Em razão da necessidade de avaliar a produção intelectual e artística para a qualificação dos programas de pós-graduação, a CAPES também exerce uma importante regulação nos periódicos científicos, trabalhos artísticos e nos livros publicados, feito mediante o sistema avaliativo Qualis e suas três divisões: Qualis periódicos, Qualis livros e Qualis artístico.

Criado em 1998 e modificado sob o prisma de seu atual modelo, em 2007, o Qualis periódicos se trata de um sistema nacional de avaliação onde as revistas científicas são classificadas em diferentes estratos dependendo do maior ou menor cumprimento de determinados requisitos. Essa estratificação demonstra o grau de excelência e qualidade da revista utilizada para a publicação. Ademais, o Qualis periódicos é utilizado como avaliação e classificação da produção científica em periódicos dos programas de pós-graduação, sendo seus dados utilizados para o sistema de avaliação da CAPES.

Todas as informações fornecidas pelas instituições de ensino superior são disponibilizadas em forma de listas de acesso via internet na Plataforma Sucupira, uma ferramenta que reúne informações sobre a pósgraduação no Brasil, servindo de base para o Sistema Nacional de Pós-Graduação - SNPG. A lista fornecida não é exaustiva, trata-se de uma lista de periódicos que mediante a colheita de informações fornecidas pelos programas de pós-graduação que as utilizaram como meio de publicação no período de análise. (CAPES, 2018).

A classificação é realizada pelas 49 áreas de avaliação e passa por um processo anual de atualização. A maior qualificação é o Qualis A1, seguida por A2, B1, B2, B3, B4, B5 e C, esse último com peso zero. A classificação é realizada pelos comitês das quarenta e nove áreas de avaliação, que seguem os critérios definidos pela área e aprovados pelo Conselho Técnico-Científico da Educação Superior - CTC-ES. (CAPES, 2018).

Entende-se que os índices divulgados pelo Qualis têm a possibilidade de influenciar de maneira direta na escolha do pesquisador do veículo de publicação de seu trabalho acadêmico, criando, assim, a função para o Qualis de um poderoso indicador sobre o valor dos periódicos, produzindo uma tendência onde as revistas se tornem cada vez mais restritivas em seu acesso para publicação. (SILVA, 2009, p. 120).

O Qualis artístico foi implementado em 2007 e é voltado especificamente para a área de avaliação Artes e Música. Ele considera que a produção artística, quando vinculada aos programas de pós-graduação pertencentes à essa área, tenha sua avaliação utilizando os mesmos critérios e avaliações compreensíveis às demais áreas de avaliação, sendo considerada, equiparadamente, uma produção bibliográfica. Para essa categoria do Qualis, o impacto da obra, sua repercussão e abrangência e o grau de vinculação com a linha de pesquisa ou projeto de pesquisa com o autor são os dois aspectos norteadores na avaliação realizada pela CAPES. (CAPES, 2018). Da mesma maneira que o Qualis periódicos, sua estratificação é feita com os conceitos C, B5, B4, B3, B2, B1, A2 e A1.

Por último, o Qualis livros avalia a produção intelectual dos pesquisadores e de seus programas feita através de livros, sejam eles de uma única autoria ou editoração de coletânea de capítulos. Diferentemente das outras duas categorias do sistema avaliativo, o Qualis livros apresenta uma classificação inversa: L1, como 
estrato inferior, passando por L2, L3, L4, esse último o estrato superior e $\mathrm{LNC}^{6}$, que são aqueles não considerados na avaliação.

A grande peculiaridade da avaliação pelo Qualis livros é que estão ausentes indicadores, como o de circulação e impacto em indexadores reconhecidos, que possibilitariam mensurar a qualidade de um periódico científico em que foi publicado após avaliação qualitativa da obra, cujos "textos, dados, metodologias e contextualização são previamente examinados quando do julgamento do artigo pelos pares". (CAPES, 2018). Ou seja, como os livros são obras únicas, a avaliação do seu "veículo de publicação" seria altamente subjetiva.

Por último, a CAPES exerce a atividade de fomento à pesquisa e ao ingresso e manutenção na pósgraduação por meio de premiações, concessões de bolsas e auxílios de pesquisa.

\section{A compreensão sobre a noção de Agência Reguladora no Brasil}

Resumidamente, a reforma administrativa, encabeçada por Luiz Carlos Bresser Pereira, do extinto Ministério da Administração Federal e Reforma do Estado - MARE, buscou implementar na burocracia do Poder Público uma reforma gerencial que, estrategicamente, visava obter o controle posterior de resultados, a garantia da autonomia do administrador na gestão de recursos humanos e a definição precisa dos objetivos do administrador público em sua entidade, órgão ou departamento. (NOHARA, 2012, p. 81).

A reforma da Administração objetivava repassar as atividades consideradas como não exclusivas do Estado para a execução pela sociedade civil, tendo inicialmente, como foco prioritário, não os serviços sociais ${ }^{7}$, mas os serviços públicos privativos. Em outras palavras, voltava-se à privatização de atividades econômicas em sentido estrito exploradas diretamente pelo Poder Público. Porém, os serviços sociais passam também a serem considerados questões centrais para a continuidade do processo de reforma administrativa. (GABARDO, 2009, p. 110-111).

Para Bresser-Pereira (1996, p. 7), houve, nesse aspecto, a tarefa de redefinição das funções do Estado, surgida em decorrência da globalização. O autor entende que a regulação e intervenção continuariam necessárias em áreas sensíveis (saúde, educação, cultura, infraestrutura, ciência e tecnologia), não mais apenas garantindo o equilíbrio social, mas, também, capacitando os agentes econômicos a competir a nível mundial.

Dessa maneira, houve a delegação ao privado de serviços anteriormente sob incumbência do Estado e criou-se, juntamente com esse processo de diminuição da máquina administrativa, entidades com personalidade jurídica e descentralizadas para regulamentar essas atividades. Melhor dizendo, converteu-se o processo de descentralização (ARAGÃO, 2013, p. 213) por delegação legal, que originavam as novas entidades

\footnotetext{
6 Os "LNC" são desconsiderados "por não terem conteúdo vinculado às áreas de concentração e linhas de pesquisa dos Programas ou por não se tratarem de livros de caráter acadêmico". Em: CAPES (2018).

7 Emerson Gabardo advertiu, mencionando Carlos Ari Sundfeld, que a utilização do termo "serviço social" abarca os serviços sem titularidade estatal, ou não privativos. Em: GABARDO, 2009, p.110. O segundo autor, então, os conceitua como "à semelhança dos serviços públicos, atividades cuja realização gera utilidades ou comodidades que os particulares fruem direta e individualmente. No entanto, diferenciam-se daqueles por não serem de titularidade estatal. Incluem os serviços de educação (CF, arts. 205 a 208, e 210 e 214), saúde (CF, art.196 e ss.) e assistência social (CF, arts.203 e 204; 227, §1ํㅜ 226, $\left.\S 8^{\circ}\right)$, aos deficientes, jurídicos, em caso de calamidade etc.". Em: Sundfeld (2017, p. 83-84).
} 
da Administração Indireta, por descentralização por delegação negocial, com o desempenho das atividades por meio do sistema de concessão de serviços públicos. (CARVALHO FILHO, 2017, p. 516).

Neste contexto, tais entidades, intituladas como Agências reguladoras, podem ser compreendidas como instrumentos de controle estatal de atividades econômicas que a Administração Pública considere relevante regular. O Poder Público adotou uma postura de concentração regulatória normativa, deixando de lado o antigo comportamento de concentração regulatória operacional (AGUILLAR, 2016, p. 235). A elas foram atribuídas, como função principal, controlar a prestação dos serviços públicos, o exercício de atividades econômicas e a atuação da sociedade civil que passou a executá-los, com amplo poder de impor a adequação das pessoas privadas aos fins e estratégias econômicas e administrativas estatais (CARVALHO FILHO, 2017, p. 517). Além disso, possuem a incumbência de identificar falhas específicas no setor regulado para buscar evitar práticas restritivas à livre competição entre licitantes para o alcance de contratações mais adequadas às necessidades coletivas.(NOHARA, 2018, p. 608).

Como prerrogativas para o exercício desse múnus público, adotou-se um modelo pluricêntrico de Estado que afastou do poder central os critérios político-partidários de decisão, com a premissa de que, tendo liberdade de agir, as agências reguladoras poderiam realizar os objetivos fixados na lei e as políticas públicas estabelecidas pela Administração Central (ARAGÃO, 2013, p. 221) de maneira mais adequadas às especificidades de cada serviço. Assim, para que haja uma atuação eficaz, necessita de: ampla autonomia técnica, administrativa e financeira; expedir normas operacionais e de serviço, para acompanhar o ritmo do desenvolvimento do serviço público regulado; aplicar sanções com celeridade; associar a participação dos usuários no controle e fiscalização do serviço. (AZEVEDO, 1998, p. 142).

Vale destacar o seu dever-poder de realizar políticas públicas no setor regulado. Isso porque o artigo 174 da Constituição Federal prenunciou que, quando a Administração Pública atuar como agente normativo e regulador da atividade econômica, ele exercerá funções de fiscalização, incentivo e planejamento ${ }^{8}$. O que se nota, também, é a necessidade de, ao contrário do que se compreendia na autarquia, que realizado o controle de meios, houvesse o controle de resultados. (AZEVEDO, 1998, p. 142-143)

Entretanto, a independência administrativa, autonomia administrativa, financeira, funcional, patrimonial e gestão de recursos humanos são elementos que, notadamente, já existem em qualquer autarquia. O que realmente possui como diferencial em relação às autarquias é em relação à investidura e o exercício fixo do mandato dos dirigentes das agências. (MELLO, 2014, p. 178). Ou seja, os dirigentes não são livremente exoneráveis pelo Chefe do Executivo.

De fato, em comparação com as autarquias "gerais", possuem poucas diferenças. Segundo o Estatuto da Reforma Administrativa Federal, Decreto-Lei n. 200/1967, as autarquias traduzem-se em um "serviço autônomo, criado por lei, com personalidade jurídica, patrimônio e receita próprios, para executar atividades típicas da administração pública, que requeiram, para seu melhor funcionamento, gestão administrativa e

\footnotetext{
${ }^{8}$ Quanto à questão de planejamento, Vanice Regina Lírio do Valle entende que "a enunciação de programas de ação contemplando cada qual as etapas que permitem a sua escolha e detalhamento - é prática que traduz objetivamente o dever de planejamento da ação estatal (art.174 da CF), dever esse que lança seus olhos para além do administrar o presente, da gestão ordinária dos fatos conjunturais, incorporando uma visão dos efeitos de longo prazo do agir do poder". Em: Valle (2016, p. 78).
} 
financeira descentralizada". Portanto, é uma pessoa jurídica criada por lei, com personalidade e natureza jurídica públicas, capacidade de autoadministração, especialização dos fins ou das atividades e sujeição ao controle de tutela.

No entanto, o que compreenderiam atividades típicas da administração pública mencionado no DecretoLei? José dos Santos Carvalho Filho (2017, p. 499) aduz que, apesar de difícil nomenclatura, tratar-se-ia da execução de serviços públicos de natureza eminentemente social e de atividades administrativas, excluindose, nesse sentido, os serviços e atividades de cunho econômico e mercantil, adequados ao escopo das empresas estatais.

Em outras palavras, as autarquias podem possuir como objeto a assistência, o fomento, gestão previdenciária, educacionais, culturais, profissionais, corporativas, ambientais, administrativas e de controle (NOHARA, 2018, p. 593-595), atividades essas de exercício típico pelo Estado por disposição constitucional expressam.

Quanto à independência no agir das agências reguladoras, qual seria o limite? Relembra Nohara que, inicialmente o Plano Diretor de Reforma do Estado buscava uma transformação jurídica da qual presenciamos hoje. Inicialmente, a ideia seria transformar as autarquias e fundações públicas existentes e que manejassem poderes da Administração Pública em agências autônomas, sob a administração por contrato de gestão, com ampla liberdade para gerir os recursos colocados à disposição. (NOHARA, 2012, p. 85)

Dessa maneira, Nohara compreende que a agência não possui independência em relação ao Poder Executivo, por aquela fazer parte da Administração Indireta, tendo a possibilidade de supervisão ministerial sobre atos que extrapolem as atribuições institucionais; ao Poder Legislativo, pois a agência deve obediência ao princípio da legalidade e à reserva legal constitucional, bem como a previsão de controle pelos Tribunais de Contas, por serem pessoas jurídicas de direito público e receberem dotações orçamentárias que lhes garantem autonomia financeira; ao Poder Judiciário $^{9}$, que podem controlar os atos das agências se violarem o ordenamento jurídico, ressalvados os casos alternativos de composição de interesses. (NOHARA, 2018, p. 622$623)$.

Outra vez, quando comparada com as autarquias comuns, estas também se submetem ao controle do Poder Central, na medida que é um poder que "assiste à Administração Central de influir sobre elas com o propósito de conformá-las ao cumprimento dos objetivos públicos em vista dos quais foram criadas, harmonizando-as com a atuação administrativa global do Estado". MELLO, 2014, p. 166).

Finalmente, diante dos elementos aqui elencados, defende-se que a Coordenação de Aperfeiçoamento de Pessoal de Nível Superior é, de fato, uma agência reguladora que norteia em nível nacional o serviço público ${ }^{10}$ de educação superior e pesquisa acadêmica. Dessa maneira, é necessário trazer, no próximo capítulo,

\footnotetext{
${ }^{9}$ É correto o posicionamento de Maurício Zockun, que entende que ao Judiciário corresponde examinar os excessos e arbítrios praticados, identificando as hipóteses que a solução adotada não condiz com o fim pretendido em lei. Ademais, ele pode atuar como legislador positivo em campo que não lhe é próprio, mas isso não o autoriza a se substituir às atividades desempenhadas pelos demais poderes, salvo quando houver falta de norma regulamentadora sobre determinada matéria e quando for o exercício de competência vinculada da Administração. Em: Zockun (2008, p.171-173).

10 “Na regulação da pós-graduação stricto sensu diversos interesses estão em disputa. A educação não é um processo único, automático e previsível; é um complexo modelo de múltiplas regulações, em constante movimento e não acabado. Por envolver a sociedade e a formação humana, a regulação da atividade educacional acompanha as mudanças do contexto social em que está inserida". Em: Hamada (2017, p. 231).
} 
as características jurídicas, as atividades que disciplinam, funções e outros elementos elencados neste capítulo e correlacionar com os fundamentos e atuação da CAPES.

Como pondera Guilherme Henrique Hamada (2017, p. 117), a fundação CAPES deixou de ser apenas uma comissão da Administração Central responsável por uma campanha no setor de ensino, transformandose numa grande estrutura que é responsável pelos rumos da pós-graduação stricto sensu brasileira.

\section{Poder Regulador sobre a pós-graduação}

A CAPES tem a titularidade e exerce o papel da Administração Pública de regular a Educação, ciência e tecnologia, em nível de pós-graduação stricto sensu. A entidade não está dissociada dos programas de pósgraduação que regula, pois a definição das políticas de pós-graduação e da sistemática do processo de avaliação são definidas e concretizadas por professores dos PPG's. Em outras palavras, a avaliação traduz os valores acadêmicos das áreas de conhecimento avaliadas e as convicções dos pares. (MACARRI; LIMA; RICCIO, 2009, p. 93).

Para Guilherme Hamada (2017, p. 230), as atividades exercidas pela CAPES precisam ser compreendidas a partir do papel constitucional do nível educacional. Isso porque "a educação é um direito social complexo, cuja importância está ligada aos fundamentos e objetivos da República, atuando como propulsora do desenvolvimento nacional".

A CAPES, com seu poder regulatório e de fomento, possui, como outras agências reguladoras, legitimidade para atuar com políticas de pós-graduação e de educação superior priorizadas na conjuntura político-econômica de cada governo, com objetivos e conceitos diferentes para desenvolvimento, o papel da comunidade acadêmica e da tecnologia e inovação. (SGUISSARDI, 2006, p. 78).

Mas em que consiste o termo regulação? Vale-se, aqui, do conceito trazido por Floriano Marques Azevedo Neto (2002, p. 14): para o autor, a regulação é a atividade estatal mediante a qual a Administração Pública, seja por intervenção direta ou indireta, condiciona, restringe, normatiza ou incentiva a atividade econômica de modo a preservar a sua existência, assegurar o seu equilíbrio interno ou atingir determinados objetivos públicos como a proteção de hipossuficiências ou consagração de políticas públicas.

Conforme mencionado em capítulo anterior, uma agência reguladora possui algumas atividades que estão sob sua incumbência em disciplinar. As que merecem destaque são: a) os serviços públicos propriamente ditos; b) as atividades de fomento e fiscalização de atividade privada; e c) as atividades que o Estado também protagoniza, mas que, paralelamente, são facultadas aos particulares exercerem. (MELLO, 2014, p. 174-175). Outrossim, as agências reguladoras objetivam mediar os interesses específicos no setor, implementa políticas públicas de acordo com as pretensões e planejamento da Administração direta, tutela os interesses dos segmentos considerados hipossuficientes. (MARQUES NETO, 2002, p. 92).

Curiosamente, na obra de comemoração dos cinquenta anos de existência da CAPES, os depoimentos e produções ali apresentados utilizam em vários momentos o termo "agência" para se referir à fundação. (FERREIRA; MOREIRA, 2001). A fundação pública em estudo notoriamente disciplina as atividades anteriormente levantadas. Primeiro, por fiscalizar uma atividade administrativa notadamente considerada como 
serviço público exercível pela Administração Pública e por particulares. Segundo, por realizar atividades de fomento e fiscalização da atividade privada por meio da avaliação das faculdades e concessão de bolsas e auxílios financeiros a projetos de universidades públicas e privadas. Terceiro, por ser a educação superior e a pesquisa e desenvolvimento atividades de ampla importância econômica e social, fato esse que é notado no escopo de outras agências reguladoras.

Nesse sentido, é possível traçar a influência da CAPES nos programas de pós-graduação nos seguintes aspectos: a) é um direcionador estratégico dos programas, na medida em que os seus parâmetros avaliativos influenciam na definição dos requisitos para a contratação dos docentes e a sua atuação (produção intelectual e formação dos discentes); b) na qualidade, pois, inegavelmente, os critérios estipulados vem influenciando o direcionamento dos esforços e investimentos da pós-graduação para a melhoria da produção intelectual docente e discente e na infraestrutura; c) na produtividade, pois a natureza quantitativa do processo avaliativo induz ao alto desempenho quantitativo de produção intelectual; d) e na inserção social, por exigir uma formação docente altamente qualificada e a participação dos programas no desenvolvimento da pós-graduação em regiões mais carentes academicamente. (MACARRI; LIMA; RICCIO, 2009, p. 92-93).

O que se percebe, assim, é que o direcionamento dos programas de pós-graduação aos níveis de qualidade desejados por meio da avaliação é, justamente, um mecanismo de regulação estatal exercido de maneira explícita pela CAPES, sendo assim, um órgão estatal regulador da pós-graduação stricto sensu brasileira. (HAMADA, 2017, p. 125). Além disso, a avaliação, no sentido de regulação e controle, vem sendo o instrumento central na reforma ou modernização conservadora da máquina pública e da educação superior. (SGUISSARDI, 2006, p. 52). ${ }^{11}$

Ademais, para José Dias Sobrinho (2003, p. 35), sob a concepção do “Estado Avaliador”, o processo de avaliação da educação superior brasileira tem sido praticada como um instrumento privilegiado de regulação, que ultrapassa as barreiras burocráticas de controle, modelação e fiscalização. Como denota Anna Elizabeth Galvão Coutinho Correia (2012, p. 191-192), que analisou a influência da CAPES sobre os programas de pósgraduação em Física, percebe-se que a referida entidade intervém quantitativa e qualitativamente nesses programas, em razão de que as universidades e docentes são avaliados por todas as atividades exercidas. Mais especificamente, o método mais comum de avaliação é por meio da produção científica. Assim, no caso em análise, a pesquisadora percebeu que nos programas com conceito CAPES 7, a maioria dos docentes são altamente produtivos em se tratando de publicação de artigos científicos.

Em outro exemplo, agora no setor de educação física, a CAPES também influencia diretamente. A produção intelectual nessa área do conhecimento vem sendo fomentada no sentido de se produzir mais a despeito da qualidade. ${ }^{12}$ Tendo como exemplo um dos pilares da avaliação dos PPG's, a análise da produção

\footnotetext{
11 "Dada a tradição da universidade brasileira de falta de autonomia em relação ao Estado e, portanto, também de ausência de cultura de avaliação e autoavaliação institucional e porque sempre se ateve a responder a demandas externas, estatais, de avaliação, a relação da comunidade acadêmica da pós-graduação com o "Modelo CAPES de Avaliação" é de profunda ambiguidade. Ao mesmo tempo em que o reconhece como legítimo, o teme. Ao mesmo tempo em que o teme, e talvez por não identificar adequadamente sua natureza e especificidade de regulação e controle em nome do Estado, atribui-Ihe todo o poder de definir a efetiva qualidade que devem ter os programas de pós-graduação. E a qualidade da pós-graduação brasileira passa a ser a que for definida pelo "Modelo CAPES de Avaliação". Em: Sguissardi (2006, p. 79).

12 Complementarmente, os autores entendem que "o sistema de avaliação da produção científica pode influenciar nas ações dos sujeitos envolvidos com a pesquisa na Educação Física, direcionando suas práticas para investigações que possibilitem um acúmulo de capital científico, representado pela somatória de artigos publicados, procurando, principalmente o reconhecimento e o prestígio no meio acadêmico-científico, ignorando questões que
} 
científica via artigos é feita por critérios pré-estabelecidos que norteiam tanto os avaliadores quanto os avaliados, nesse sentido, definir critérios para a classificação de revistas é, em resumo, estabelecer a política que determinará os rumos da própria forma de se fazer pesquisa no país. (HACHEM, 2018). Isso porque a tendência natural, em razão da busca de melhores pontuações para o programa, é interessar-se em veículos para publicação mais bem classificados.

Luis Felipe Nascimento (2009, p. 581) defende que a necessidade de alcançar boas pontuações na avaliação cria, de fato, uma pressão para que os professores publiquem em periódicos e, consequentemente, tem gerado um alto nível de estresse, com uma tendência de adaptação e, como resultado, a adaptação docente aos critérios, reduzindo sua dedicação às atividades pouco ou não pontuadas.

Para Rita de Cássia Barradas Barata (2016, p. 16-17), Diretora de Avaliação da CAPES, o Qualis periódicos: não é uma base de indexação de periódicos, não é uma base bibliométrica e não permite o cálculo de nenhuma medida de impacto, não é uma fonte adequada de classificação da qualidade dos periódicos científicos para outros fins que não a avaliação dos programas de pós-graduação, não é uma classificação absoluta e, finalmente, não é uma ferramenta que possa ser utilizada em avaliações do desempenho científico do pesquisadores.

A avaliação das revistas científicas, entretanto, não deve ser considerada apenas como mero instrumento a ser utilizado no processo de avaliação dos programas de pós-graduação. Sua função ultrapassa essa concepção inicial. Restringir teoricamente sua atuação ignora a realidade dos seus impactos perante a comunidade acadêmica, segrega a pesquisa científica que ocorre dentro e fora dos institutos de ensino superior e entre as diversas áreas do conhecimento. (GABARDO; HACHEM; HAMADA, 2018, p. 181).

De fato, a avaliação realizada pela fundação pública é caracterizada por três eixos: a) feita por pares oriundos de diferentes áreas do conhecimento e reconhecidos por sua reputação intelectual; b) possui natureza meritocrática, levando à classificação dos e nos campos disciplinares; c) ela associa reconhecimento e fomento, definindo assim políticas e estabelecendo critérios para o financiamento de programas. (BRASIL, 2011, p. 125).

Ademais, insta relembrar que a própria CAPES possui a competência de autorizar, punir ou encerrar um programa de pós-graduação dependendo da avaliação que obter. Somente com a entrada do programa de mestrado e doutorado no Sistema Nacional de Pós-Graduação possibilita que os diplomas emitidos pela instituição sejam reconhecidos pelo Conselho Nacional de Educação do MEC com base na avaliação realizada pela CAPES.

A Portaria $n . .161$ de 2017 da CAPES disciplina o processo de avaliação de propostas de cursos novos e deixa explícito que as propostas serão enviadas à fundação para a avaliação e posterior parecer final do CTCES. Após o resultado definitivo, as decisões tomadas serão encaminhadas à Câmara de Educação Superior do Conselho Nacional de Educação para que delibere e depois tenha a homologação pelo Ministro de Estado da Educação. Quando, no entanto, uma proposta de um novo programa de mestrado ou doutorado ou um existente não alcança a nota mínima 3, fica ameaçado de não integrar o Sistema Nacional de Pós-Graduação.

emergem da sociedade e que precisam de uma atenção especial de toda a comunidade científica e daqueles envolvidos com a produção de conhecimento na Educação Física". Em: Maschlewski. Silva e Soriano (2011, p.113). 
Consequentemente, com o não reconhecimento, o programa de pós-graduação não poderá mais aceitar novos discentes, emitir diplomas, receber determinados tipos de auxílios financeiros, bolsas e outros tipos de fomento.

O poder da avaliação e da condução normativa da pós-graduação deixa explícito o poder de polícia que a fundação exerce. Essa espécie de atividade consiste, assim, na imposição de limitações administrativas previstas em lei, na fiscalização, e na repressão de atividades não compatíveis com o bem-estar geral. (NOHARA, 2018, p. 652).

A CAPES também fomenta os programas pertencentes ao SNPG. Além da tradicional concessão de bolsas nos níveis de mestrado, doutorado, doutorado sanduíche e pós-doutorado, a entidade também é responsável por apoiar os programas com repasses diretos de recursos financeiros. Se não bastasse isso, também vem realizando ações indutivas, com o desenvolvimento de projetos com formação de pessoal em áreas consideradas estratégias pelo governo em termos de desenvolvimento econômico, científico, tecnológico e segurança nacional. (BRASIL, 2011, p. 260).

De acordo com o Sistema de Informações Georreferenciadas da CAPES - GEOCAPES, no ano de 2016, a fundação dedicou cerca de $R \$$ 3.112.681.395,00 para a concessão de bolsas de pesquisa. Além disso, distribuiu 100.433 bolsas das mais diversas categorias de financiamento. O fundo dedicado foi partilhado entre os 4295 programas que pertencem ao SNPG. (CAPES, 2018).

Como o próprio texto do Plano Nacional de Pós-Graduação de 2011-2020 assentiu, "a expansão e consolidação do SNPG são uma decorrência do importante papel desempenhado pela CAPES que sempre traçou as suas orientações estabelecendo as metas e objetivos a serem alcançados, em colaboração com a comunidade científica". (BRASIL, 2011, p. 155). Afinal, o sistema de pós-graduação constitui um conjunto de universidades, com perfis e propostas diversos, tendo autonomia para criar ou fechar cursos, mas depende do financiamento da CAPES e de seu ranking, que lhes atribui o selo de qualidade necessário. (BRASIL, 2011, p. 127).

Valdemar Sguissardi (2006, p. 76) atestou que a realidade da CAPES como uma agência financiadora é uma entidade que premia, pune e exclui de acordo com a classificação obtida pelo programa com base em procedimentos de avaliação (com mensurações, quantificações e qualificações próprios), mesmo que se utilizando de representatividade da comunidade científica, que também demonstram interesse no que o autor chama de "corrida competitiva por credenciais acadêmico-científicos". Esses fatos comprovam que o modelo avaliativo se caracteriza como um conjunto de procedimentos e atos de regulação e controle para "acreditação ou garantia pública de qualidade" no interesse do Poder Público e da sociedade do que um modelo típico de avaliação (avaliação educativa ou diagnóstico-formativa). Outrossim, o que se percebeu também devido o sistema de pós-graduação nacional deter pouca autonomia, os modelos de avaliação têm se substituído ao processo de autoavaliação das universidades, necessárias para a comunidade acadêmica.

A título comparativo, é possível ilustrar as características da Agência Nacional do Petróleo e a Agência Nacional de Energia Elétrica. A ANP, de acordo com a o sétimo artigo da Lei n.o 9478 de 1997, possui a incumbência, dentre várias, de autorizar a atividade de comercialização de gás natural; regular e autorizar as atividades de comercialização de biocombustíveis; fomentar a pesquisa e adoção de novas tecnologias na 
exploração, produção, transporte, refino e processamento; implementar a política nacional de petróleo, gás natural e biocombustíveis; e promover a licitações para a concessão de exploração e produção.

Já a ANEEL, segundo o artigo terceiro da Lei n. 9427 de 1996, tem como principal missão: implementar as políticas da Administração Pública Federal para a exploração da energia elétrica; estabelecer as metas a serem alcançadas pelas concessionárias e permissionárias do serviço público de distribuição elétrica; e estabelecer mecanismos e regular o serviço concedido, com fiscalização permanente da prestação do serviço de energia elétrica.

Nos exemplos citados, sem considerar a nítida diferença quanto ao objeto regulado, as agências reguladoras e a CAPES exercem funções quase idênticas sobre o serviço público e a atividade econômica, quais sejam: regulação, fiscalização e fomento.

Outra característica comum entre as agências reguladoras é seu controle concorrencial, como ocorre de maneira mais explícita na ANAC, com certa pluralidade de empresas de transporte aéreo privado, na ANS, com os variados planos de saúde privados e na ANATEL, regulando as inúmeras empresas de telecomunicações atuantes no Brasil. Segundo Alexandre dos Santos de Aragão, todas as agências reguladoras têm, na realidade, entre os interesses primários, a proteção e ampliação da concorrência. (ARAGÃO, 2013, p. 308). Na prática, o modelo regulatório da CAPES, em razão de suas características, tende a incentivar a competição entre os programas de uma mesma área, além de substituir a autonomia pela heteronomia e conduzir à conformidade. (SGUISSARDI, 2008, p. 861).

Quanto à característica estrutural das agências reguladoras no Brasil, sabe-se que ela consiste na impossibilidade de exoneração ad nutum aos seus dirigentes e periodicidade determinada que lhe dão a característica de serem "autônomas". Não parece, sem embargo, que a ausência dessas características seja um elemento essencial para deslegitimar o status de agência reguladora da CAPES, devido ao seu quaseirrestrito-poder e impacto econômico e social que possui sobre a pesquisa científica brasileira.

Relativamente a essa maior autonomia delegada às agências, dada pelo mandato fixo de seus dirigentes e previsão de quarentena dos diretores desvinculados, não impossibilita o Poder Público de exercer controle sobre elas. Fato é que em qualquer entidade pertencente à Administração Pública sofre o controle hierárquico e o controle político. Regina Silva Pacheco (2006, p. 539-540) sustenta que o controle hierárquico consiste na relação de autoridade que se estabelece entre o nomeador (no caso, o chefe do Poder Executivo) e o nomeado. Tradicionalmente, esse controle é exercido pelo Presidente da República por meio da livre nomeação e exoneração. Nesse tipo de controle, a autonomia das agências e o controle do Poder Executivo são usualmente considerados antinômicos em razão de o controle residir basicamente no poder de nomeação/demissão dos dirigentes pelo Presidente.

No caso do controle político, exige-se uma supervisão permanente exercida por diferentes atores além do Poder Executivo, como uma ação simultânea e complementar dos demais poderes. Sem o controle simultâneo praticado pelo Poder Legislativo e Poder Judiciário, estar-se-ia diante do controle hierárquico. Contudo, o controle político não se dá por meio do poder de demissão dos dirigentes, mas por outros mecanismos. (PACHECO, 2006, p. 540). 
Até o momento, a nomeação da diretoria da CAPES é feita sem periodicidade determinada e com livre exoneração, como observado nos mandatos de alguns dirigentes da entidade: Abílio Afonso Baeta Neves, que encabeçou a Coordenação por nove anos (1995-2003) e Jorge Almeida Guimarães, que presidiu a instituição por onze anos (2004-2015).

O que necessitaria, nesse aspecto formal, seria somente a promulgação de uma nova lei pelo Congresso Nacional que acrescentasse algum dispositivo na normativa da Lei 8.405 de 1992 para garantir a proibição da exoneração ad nutum e a periodicidade nos cargos de diretoria. A alteração não implicaria numa mudança estrutural da CAPES, mas somente afetaria questões secundárias em sua diretoria. Como afirma Irene Nohara (2018, p. 601), "nada impede que a lei estabeleça normas especiais para determinada autarquia ou categoria de autarquias".

Segundo as disposições da lei n. 99986 de 2000, que discorre sobre a gestão de recursos humanos das Agências reguladores, ressalta que a agência reguladora deve ser dirigida em regime de colegiado, por um Conselho Diretor ou Diretoria composta por Conselheiros ou Diretores (artigo quarto). Além disso, o artigo quinto determina que os membros dessa Diretoria deverão ser brasileiros, de reputação ilibada, com formação universitária e elevado conceito no campo de especialidade dos cargos que serão nomeados, sendo cumpridos esses requisitos, submetidos à nomeação pelo Presidente da República após aprovação do Senado Federal.

Alexandre de Aragão (2013, p. 601) entende que a formação técnico-especializada necessária aos dirigentes das agências reguladoras pode ser de conteúdo certo, quando previsto o termo "formação universitária" ou conceitos jurídicos indeterminados, quando expressa "elevado conceito no campo de especialidade dos cargos". Outrossim, defende que pode imperar o controle judicial, quando ocorrer o descumprimento tanto do requisito "formação universitária" quando "elevado conceito de especialidade do cargo".

Deveras, conforme explanado no primeiro capítulo, existe na estrutura administrativa da CAPES uma Diretoria-Executiva encabeçada pelo seu Presidente, bem como satisfaz os outros requisitos da Lei $n . .9986$, a saber: a diretoria é escolhida entre professores com formação universitária elevada, por ter a titulação de doutor e, por abranger todas as áreas do conhecimento, a escolha de uma reputação em qualquer campo científico também atende o requisito "elevado conceito no campo de especialidade do cargo". Admite-se, no entanto, que isso não consiste em uma regra positivada, mas sim um costume gerado em razão do predomínio da comunidade acadêmica e no objeto que a CAPES regula que é a pós-graduação. A prática, contudo, demonstra que todos os dirigentes da instituição detinham elevada formação e conhecimento técnico.

A educação, ciência e tecnologia, devido a sua obrigatoriedade de provimento pelo Estado e a autorização constitucional dando possibilidade do exercício da atividade econômica de educação em todos os níveis de ensino, entendeu-se que a papel regulatório do Estado se caracteriza em um regime híbrido. Em outras palavras, ela regulamenta um serviço público propriamente dito e uma atividade econômica.

Em razão disso, surgem questionamentos, como os levantados por Valdemar Sguissardi (2008, p. 862): qual seria a concepção da educação superior? De Direito e bem público ou um serviço e bem privado/mercantil? 
Qual seria o modelo de expansão da educação superior, estatal ou privado? Qual seria a natureza da regulação e controle, se privilegia a competição, a eficiência e eficácia típica de mercado?

Ademais, numa agência reguladora, sabe-se que há uma pluralidade de interesses, como a universalização dos serviços sob sua regulação, a proteção de consumidores, o desenvolvimento tecnológico nacional, a atração de investimentos estrangeiros, a ampliação da concorrência e a garantia do equilíbrio econômico-financeiro. (ARAGÃO, 2013, p. 306). Mas, ao contrário do entendimento de Alexandre Santos de Aragão, a existência de interesses díspares (públicos e privados) e o dever das agências reguladoras de buscar, dentro do mandamento de otimização que lhes é inerente, a compatibilização possível entre eles para o alcance do consenso, não supera a supremacia do interesse público. ${ }^{13}$ Longe disso, o consenso entre os diversos interesses, atendendo o interesse da coletividade é a verdadeira supremacia do interesse público.

Como assenta Floriano Marques Neto (2002, p. 20), com a vinda das autarquias em regime especial para a regulação de serviços públicos, há um grande impacto causado entre a separação entre o operador e regulador ensejado pela delegação da exploração de serviço público aos particulares, que implica em profunda transformação no panorama regulatório, tornando mais complexa a regulação sobre atividades econômicas. Outro impacto ainda maior é na introdução da competição na exploração dessas atividades. Surgiu-se, assim, o entendimento que o serviço público seria uma atividade que, em razão de sua importância social, justifica que a Administração reserve para si o dever de assegurar a execução da atividade, não implicando na prerrogativa de exploração exclusiva.

Portanto, na realidade, uma agência reguladora sempre teria a hibridez de seu objeto como característica fundamental. No setor de geração e transmissão de energia elétrica, a Eletrobras, sociedade de economia mista, divide a responsabilidade pelo atendimento do serviço público de energia elétrica com outras empresas privadas, sendo, no entanto, todas reguladas pela ANEEL.

Contudo, a ideia de hibridez defendida se volta ao objeto regulado e não na atuação do Estado (intervencionismo híbrido), apesar de também ser um fator que caracteriza a CAPES e outras agências reguladoras. Explica-se: o intervencionismo híbrido consiste na forma sobre a qual o Estado atuará na economia, utilizando-se, no caso, de elementos de atuação direta, com a organização de entidades públicas para administrar a atividade econômica e, elementos de atuação indireta, que se traduz na ideia de Estado regulador, que fiscaliza, planeja e incentiva. Em outras palavras, a ação híbrida do Estado no domínio econômico, que se traduz na ideia atual das agências reguladoras, o Poder Público, age diretamente no domínio econômico ao criar uma autarquia especial, a agência reguladora e a normatização feita pelo ente regulador em seu domínio econômico é a manifestação da ação indireta estatal. (BIZZOTTO, 2016, p. 133-135).

Finalmente, com relação à CAPES, qual seria o seu objeto híbrido? Segundo o GEOCAPES, dos 4295 PPG's existentes, $81,6 \%$ dos programas de pós-graduação são públicos (federais, estaduais e municipais),

\footnotetext{
${ }^{13}$ Ver o posicionamento de Alexandre Santos de Aragão: "as decisões das agências reguladoras dever-se-ão pautar por critérios ponderados de exercício da discricionariedade muito mais complexos do que uma ultrapassada "supremacia do interesse público": há diversos interesses públicos, alguns contraditórios entre si; há interesses de várias categorias de consumidores; os interesses das empresas reguladas podem ser antinômicos, etc. Diante disto, as agências reguladoras devem buscar, dentro do mandado de otimização que lhes é inerente, a maior compatibilização possível entre eles, compatibilização esta que, no ponto ideal, alcançaria o consenso". Em: Aragão (2013, p. 307).
} 
enquanto 18,4\% (792) são privados. Da oferta pública, 57,7\% (2478) são federais, 23\% (993) são estaduais e 0,7\% (32) são municipais. (CAPES, 2018).

Dessa maneira, o que há como peculiaridade na oferta de pós-graduação no Brasil é que, enquanto parte do mestrado e doutorado é ofertado como um serviço público, caracteristicamente realizado por meio de autarquias universitárias, a outra parte oferta o mesmo serviço (não público) seguindo o mesmo regramento, as mesmas condições e sofrendo a mesma regulação e fomento. A diferença óbvia, contudo, é que na seara privada o curso possui fins lucrativos e/ou comunitários.

Em todos os programas submetidos à avaliação da CAPES se centraliza a análise de questões fundamentais como o corpo docente, produção intelectual, linhas de pesquisa, estrutura curricular do curso, estrutura física e corpo discente. ${ }^{14}$ Não se trata, assim, de uma livre atividade comparada às outras atividades econômicas com livre iniciativa e concorrência como garantida pela Constituição Federal. A seara da educação em nível de pós-graduação no Brasil, a despeito de sua autorização ao exercício da sociedade civil, é caracterizada com ampla regulação sobre a entrada dos agentes no mercado, constante fiscalização, pouca autonomia na gestão de docentes, exigências de produtividade e infraestrutura, obrigatoriedade de colaboração com outros atores do serviço e fomento de seus agentes.

\section{Considerações finais}

Entende-se também que a CAPES foi fundada para o cumprimento da obrigatoriedade constitucional do Estado em garantir o desenvolvimento da educação e da pesquisa científica brasileira, sendo, isso posto, atividades típicas. Para tanto, foram a ela incumbidos poderes normativos, fiscalizatórios e de fomento para formular políticas públicas e controlar os programas existentes para traçar o caminho ao desenvolvimento da ciência e da formação de pessoal de alta capacidade técnico-científica.

Isso posto, a fundação possui poderes amplos sobre a educação superior e pesquisa científica, tendo poderes para encerrar programas, regular a qualificação dos trabalhadores, exigir padrões de qualidade, autorizar ou negar a abertura de novos programas de pós-graduação, estabelecer obrigatoriedade de cooperação entre os PPG'S, fiscalizar a produtividade e infraestrutura e exigir contribuições para com a comunidade. É intrigante considerar que uma fundação possui poderes tão vastos como a CAPES exerce em nome do Ministério da Educação e do Governo Federal.

Além do óbvio impacto direto sobre as instituições de ensino superior, os programas de pós-graduação e pesquisadores, a CAPES também impacta, indiretamente, a sociedade como um todo. Como demonstrado, a fundação pública encabeça o processo de formulação de políticas públicas para o desenvolvimento científico e da pós-graduação brasileira. A partir do momento que exige o desenvolvimento de programas de ponta, a realização de projetos que visem o beneficiamento da sociedade, a colaboração entre os diferentes PPG's para garantir o acesso à pós-graduação nas regiões menos desenvolvidas e, principalmente, fomentar, por meio de

\footnotetext{
14 Depoimento de Rosana Arcoverde Bezerra Batista. Em: FERREIRA, Marieta de Moraes; MOREIRA, Regina da Luz. Capes, 50 anos: depoimentos ao CPDOC/FGV. Brasília: CAPES, 2001, 238 p.
} 
financiamento e concessão de bolsas, projetos e pesquisadores para setores de relevância para a segurança nacional, economia e desenvolvimento social, é inegável dizer que a CAPES gera impactos na sociedade brasileira.

Todas essas considerações não pretendem, contudo, descaracterizar a importância da fundação para a pós-graduação stricto sensu nacional. A principal questão é: devido aos seus amplos poderes e alta relevância no contexto da academia, o seu status como fundação pública não prevalece, dado ao fato que a CAPES consegue desenvolver, a mando da Administração Central, a política que entender para a educação superior. Assim, sua realidade de fato é: a CAPES é a agência reguladora da educação superior e da pesquisa científica brasileira.

\section{Referências}

ADDOR, Nicolas. A liberdade científica como requisito para um Estado democrático. In: BETTES, Janaína Maria; NASCIMENTO NETO, José Osório do; FURIATTI, Luiza de Araújo; SOUZA, Maria Augusta Oliveira de. (Orgs.). Justiça e democracia. p. 243-254, Curitiba: Íthala, 2018.

ADDOR, Nicolas. CAPES: a agência reguladora da pesquisa científica. Porto Alegre: Editora Fi, 2019.

AGUILLAR, Fernando Herren. Direito Econômico: do direito nacional ao direito supranacional. 5. Ed. São Paulo: Atlas, 2016.

ARAGÃO, Alexandre Santos de. Agências reguladoras e a evolução do direito administrativo econômico. 3. Ed. Rio de Janeiro: Forense: 2013.

AXT, Margarete. O pesquisador frente à avaliação na pós-graduação: em pauta novos modos de subjetivação. Psicologia \& Sociedade, v. 16, p. 69-85, 2004.

AZEVEDO, Eurico de Andrade. Agências reguladoras. Revista de Direito Administrativo. Rio de Janeiro, v. 213, p. 141-148, jul./set. 1998.

BARATA, Rita de Cássia Barrradas. Dez coisas que você deveria saber sobre o Qualis. Revista brasileira de Pós-Graduação, Brasília, v. 13, n. 30, p. 13-40, jan./abr. 2016.

BIZZOTTO, Daniel Augusto Arouca; SOUSA, Lorena Ribeiro de Carvalho. O intervencionismo híbrido e a autonomia do Banco Central do Brasil. Revista de Estudos Jurídicos UNA, Belo Horizonte, v. 3, n. 1, p. 131-145, 2016.

BRASIL. Ministério da Educação. Coordenação de Aperfeiçoamento de Pessoal de Nível Superior,. Plano Nacional de Pós-Graduação (PNPG) 2011-2020: Volume I. Brasília: CAPES BRESSER-PEREIRA, Luiz Carlos. Da administração pública burocrática à gerencial. Revista do Serviço Público, v. 120, n. 1, p. 7-40, jan./abril 1996.

CAPES. Documento de área: Ensino 2016. Disponível em:

https://capes.gov.br/images/documentos/classifica\%C3\%A7\%C3\%A3o de livros 2017/46 ENSI class livros jan2017.pdf. Acesso em: 01 jul. 2018.

CAPES. Sistema de informações georreferenciadas - GEOCAPES. Disponível em:

https://geocapes.capes.gov.br/geocapes/. Acesso em: 20 jul. 2018.

CARVALHO FILHO, José dos Santos. Manual de Direito Administrativo. 31. Ed. São Paulo: Atlas, 2017. 
COORDENAÇÃO DE APERFEIÇOAMENTO DE PESSOAL DE NÍVEL SUPERIOR. Competências.

Disponível em: http://www.capes.gov.br/acessoainformacao/80-conteudo-estatico/acesso-a-informacao/5418-

competencias. Acesso em: 25 jun. 2018.

COORDENAÇÃO DE APERFEIÇOAMENTO DE PESSOAL DE NÍVEL SUPERIOR. O que é a plataforma sucupira? Disponível em: http://www.capes.gov.br/avaliacao/plataforma-sucupira. Acesso em: 20 jul. 2018.

COORDENAÇÃO DE APERFEIÇOAMENTO DE PESSOAL DE NÍVEL SUPERIOR.. Perguntas frequentes. Disponível em: http://www.capes.gov.br/acessoainformacao/perguntas-frequentes/avaliacao-da-posgraduacao/7422-qualis. Acesso em: 30 jun. 2018.

COORDENAÇÃO DE APERFEIÇOAMENTO DE PESSOAL DE NÍVEL SUPERIOR. Qualis-Periódicos. Disponível em: https://sucupira.capes.gov.br/sucupira/. Acesso em: 18 jul. 2018.

CORREIA, Anna Elizabeth Galvão Coutinho Correia. A influência exercida pelo sistema de avaliação da CAPES na produção científica dos programas de pós-graduação em física. Tese (Doutorado em Ciência da Informação da Universidade Federal de Minas Gerais). 215 p. 2012.

CUNHA, Luiz Antônio Constant Rodrigues da. A pós-graduação no Brasil: função técnica e função social. Rev. adm. empres., v. 14, n. 5, p. 66-70, out. 1974.

DIAS SOBRINHO, José. Avaliação da Educação Superior: regulação e emancipação. In: DIAS SOBRINHO, José; RISTOFF, Dilvo I. (Orgs.). Avaliação e compromisso público: a educação superior em debate. Florianópolis: Insular, p. 35-52, 2003.

FERREIRA, Marieta de Moraes; MOREIRA, Regina da Luz. Capes, 50 anos: depoimentos ao CPDOC/FGV. Brasília: CAPES, 2001.

GABARDO, Emerson. Interesse Público e subsidiariedade: o Estado e a Sociedade civil para além do bem e do mal. Belo Horizonte: Fórum, 2009.

GABARDO, Emerson; HACHEM, Daniel Wunder; HAMADA, Guilherme Henrique. Sistema Qualis: análise crítica da política de avaliação de periódicos científicos no Brasil. Revista do Direito, v. 1, n. 54, p. 144-185, jan./abr. 2018.

HACHEM, Daniel Wunder. A avaliação de revistas estrangeiras pelo Qualis no Direito. Disponível em: http://www.direitodoestado.com.br/colunistas/daniel-wunder-hachem/a-avaliacao-de-revistas-estrangeiraspelo-qualis-no-direito. Acesso em: 18 jul. 2018.

HAMADA, Guilherme Henrique. O sistema regulatório de avaliação dos programas de pós-graduação stricto sensu no Brasil. 2017. 284 f. Dissertação (Mestrado em Direito) - Pontifícia Universidade Católica do Paraná, Curitiba, 24 mar. 2017.

MACARRI, Emerson Antonio; LIMA, Manolita Correia; RICCIO, Edson Luiz. O uso do sistema de avaliação da CAPES por Programas de Pós-Graduação em Administração no Brasil. Revista de Ciências da Administração, v. 11, n. 25, p. 68-96, set./dez. 2009.

MARQUES NETO, Floriano Azevedo. A nova regulação dos serviços públicos. Revista de Direito Administrativo, v. 228, p.13-29, abr./jun. 2002.

MARQUES NETO, Floriano Azevedo. A nova regulação estatal e as agências independentes. Em: SUNDFELD, Carlos Ari. (Coord.). Direito administrativo econômico. São Paulo: Malheiros, 2002.

MASCHLEWSKI, Camila; SILVA, Priscilla Maia da; SORIANO, Jeane Barcelos. A influência do sistema de avaliação QUALIS na produção de conhecimento científico: algumas reflexões sobre a Educação Física.

Motriz, v. 17, n. 1, p. 104-116, jan./mar. 2011.

MELLO, Celso Antônio de. Curso de Direito Administrativo. 31. Ed. São Paulo: Malheiros, 2014. 
NASCIMENTO, Luis Felipe. Modelo CAPES de avalição: quais as consequências para o triênio 2010-2012? Administração: Ensino e Pesquisa, v. 11, n. 4, p. 579-600, out.-dez./2009.

NOHARA, Irene Patrícia. Reforma administrativa e burocracia: impacto da eficiência na configuração do direito administrativo brasileiro. São Paulo: Atlas, 2012.

NOHARA, Irene Patrícia. Direito Administrativo. 8. ed. São Paulo: Atlas, 2018.

PACHECO, Regina Silvia. Regulação no Brasil: desenho das agências e formas de controle. Revista de Administração Pública, v. 40, n. 4, p. 523-543, jul./ago. 2006.

PAULA, Luiz Fernando de. Sistema financeiro, bancos e financiamento da economia: uma abordagem keynesiana. Rio de Janeiro: Elsevier, 2014.

SGUISSARDI, Valdemar. A avaliação defensiva no "modelo CAPES de avaliação" - É possível conciliar avaliação educativa com processos de regulação e controle do Estado? Perspectiva, v. 24, n. 1, p. 49-88, jan./jun. 2006.

SILVA, Antonio Ozaí da. A sua revista tem QUALIS? Mediações, v. 14, n. 1, jan./jun. 2009.

SUNDFELD, Carlos Ari. Fundamentos de Direito Público. 5. Ed. São Paulo: Malheiros, 2017.

VALLE, Vanice Regina Lírio do. Políticas Públicas, direitos fundamentais e controle judicial. 2. Ed. Belo Horizonte: Fórum, 2016.

ZOCKUN, Maurício. A separação dos poderes e o poder judiciário como legislador positivo e negativo.

Revista Trimestral de Direito Público, v. 47, p. 162-173, 2008. 